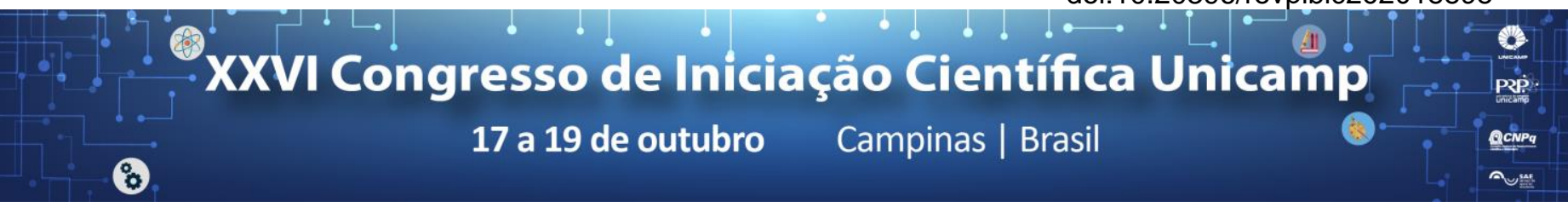

\title{
Continuous Flow Synthesis of Terpene-Based Monomers for Green Polymers Production.
}

\section{Lucas P. Fernandes*, Renan Galaverna, Gustavo R. Gomes and Julio C. Pastre.}

\begin{abstract}
The synthesis of monomers for the production of novel green polymers was evaluated in continuous flow conditions using terpenes as dienes and maleic anhydride as dienophile for the [4+2] Diels-Alder cycloaddition reaction. The hydrogenation reaction was also evaluated to prevent the retro-Diels-Alder and to expand the reactional scope by producing adducts with distinct characteristics of structures and reactivity. Fourteen different monomers were obtained in good yields in flow regime.
\end{abstract}

\section{Key words:}

Flow chemistry, Diels-Alder, Terpenes

\section{Introduction}

Polymeric materials that incorporate renewable bio-based building blocks such as terpenes, provide a necessary alternative to our historical dependence on petroleumbased polymers. In that way, different terpenes such as $\alpha$ and $\beta$-pinene, myrcene, phellandrene, limonene, terpinene have been applied to produce bio-based polymers. ${ }^{1}$

In this study, continuous flow processes were applied to the production of monomers for green polymer synthesis using terpenes as dienes and maleic anhydride as dienophile in a [4+2] Diels-Alder reaction.

\section{Results and Discussion}

The synthesis of monomers started with the evaluation and optimization of the cycloaddition reaction using $\alpha$-terpinene as diene (scheme 1), followed by the hydrogenation reaction (table 1).

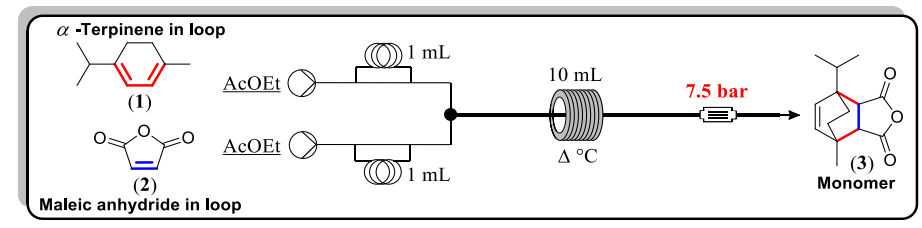

Scheme 1: Diels-Alder reaction using $\alpha$-terpinene as diene.

Total conversion (99\%) was achieved using $0.25 \mathrm{~mL} \mathrm{~min}{ }^{-1}$ at $140^{\circ} \mathrm{C}$ in $40 \mathrm{~min}$.

Table 1: Heterogeneous catalysis for hydrogenation reaction in flow regime
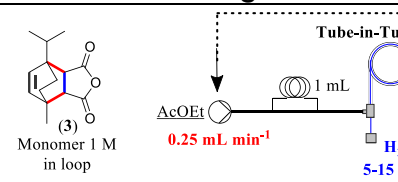

\begin{tabular}{ccccc}
\hline Entry & $\begin{array}{c}\text { Temperature } \\
\left({ }^{\circ} \mathbf{C}\right)\end{array}$ & $\begin{array}{c}\text { Time } \\
(\mathbf{m i n})\end{array}$ & $\begin{array}{c}\mathbf{H}_{2} \\
(\mathbf{b a r})\end{array}$ & $\begin{array}{c}\text { Conversion } \\
(\mathbf{6})\end{array}$ \\
\hline $1^{[\mathrm{c}]}$ & r.t. & 4 & 5 & 2 \\
$2^{[c]}$ & r.t. & 4 & 10 & 5 \\
$3^{[c]}$ & r.t. & 4 & 15 & 10 \\
$4[c]$ & 70 & 4 & 15 & 4 \\
$5^{[\mathrm{d}]}$ & r.t. & 330 & 15 & 100 \\
\hline
\end{tabular}

[a] Column details: Glass column with $750 \mathrm{mg}$ of $\mathrm{Pd} / \mathrm{C}$ (5\% wt.) ${ }^{[b]}$ Conversion was determined by GC-MS. [c] The reaction was conducted in a single-pass experiment. [d] It was recycled through the system.

The scheme 2 show the synthesis in two steps made in sequence on continuous flow using a tube-in-tube reactor.
For total conversion of monomer 3 , a recycle (entry 5 ) was necessary and $\mathrm{Pd} / \mathrm{C} 5 \%$ wt. was replaced by $30 \%$ wt. to decrease the reaction time (80 $\mathrm{min})$.

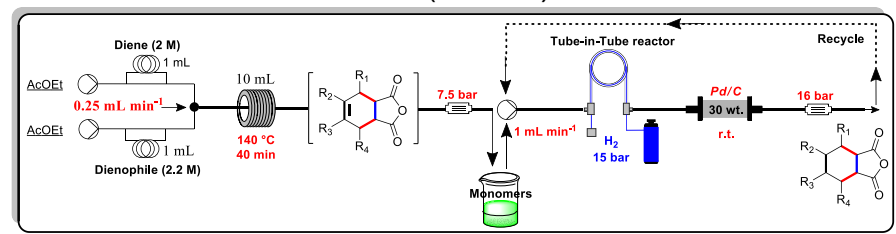

Scheme 2: Sequential Diels-Alder reaction and heterogeneous hydrogenation in flow regime.

With these results, the scope was expanded using six different terpenes as shown in the scheme $3.1,3-$ Cyclohexadiene was used as a control in the process.

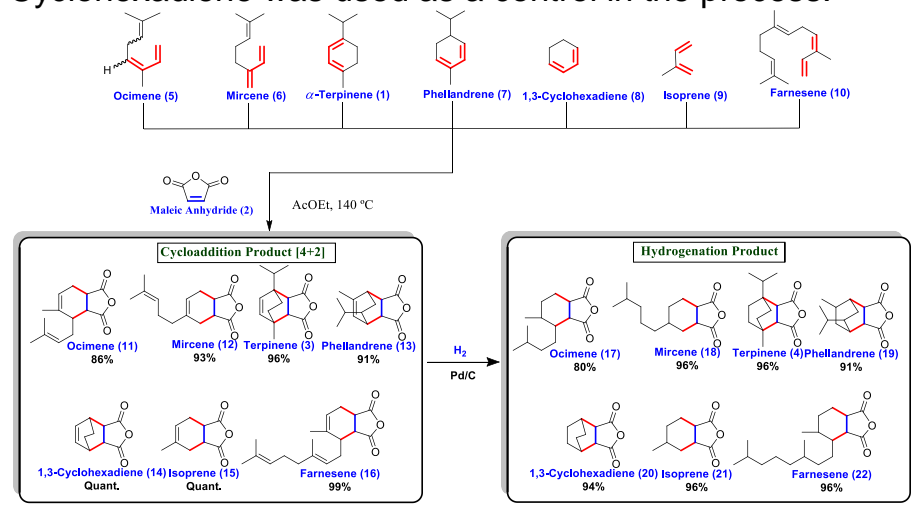

Scheme 3: Scope using different terpenes as dienes.

\section{Conclusions}

The strategy adopted here allowed the synthesis of several monomers in good yields (up to $85 \%$ ) and total conversion for terpenes in only $40 \mathrm{~min}$ for the Diels-Alder reaction. The flow process offers unique possibility to the scale-up of monomers synthesis without the need to increase the size of the coil reactor as it is requested in the batch process. Work is now in progress to produce novel bio-based polymers with these terpene-based monomers using polyols and polyamines as chain propagation agents.

\section{Acknowledgement}

The authors gratefully acknowledge financial support from FAPESP, CNPq CAPES and FAEPEX.

Perry, A. W.; Fuxiang, C.; Chuanbing, T. Macromol. Rapid Commun. 2013, $34,8-37$. 